\title{
Does functional evaluation and magnetic resonance imaging finding in a case of lumbar canal stenosis co-relate: a study of 50 cases
}

\author{
Naushad Hussain, Nirmal Dhananjay Patil*, Akassh Shakya, Kalpesh Prakash Saindane
}

TNMC and BYL Medical College, Nair Hospital, Mumbai, India

Received: 14 May 2017

Revised: 25 May 2017

Accepted: 30 May 2017

*Correspondence:

Dr. Nirmal Dhananjay Patil,

E-mail: nirmalpatil2008@gmail.com

Copyright: () the author(s), publisher and licensee Medip Academy. This is an open-access article distributed under the terms of the Creative Commons Attribution Non-Commercial License, which permits unrestricted non-commercial use, distribution, and reproduction in any medium, provided the original work is properly cited.

\section{ABSTRACT}

Background: Lumbar canal stenosis is a clinical diagnosis. MRI is used many times for making the diagnosis. But does the severity of MRI findings co-relate with functional status?

Methods: 50 cases of central lumbar canal stenosis were included in the study. The MRI findings and Oswestery Disability Index score were compared.

Results: $50 \%$ of patients with severe ODI score had no Stenosis in the MRI. MRI findings do not co-relate with the functional severity of the disease $(\mathrm{p}=0.03)$.

Conclusions: MRI and ODI score does not co-relate. This study reinforces the fact that one should always treat the patient and not the MRI.

Keywords: Lumbar canal stenosis, MRI, Functional, Oswestery disability index

\section{INTRODUCTION}

H. Verbiest coined the term, "stenosis of the vertebral canal" and defined the pathologic changes that take place in the lumbar spinal canal engendered by encroachment of the canal contents by hypertrophied articular processes. ${ }^{1}$ Verbiest regarded absolute stenosis as an anteroposterior (AP) diameter of less than $10 \mathrm{~mm}$ on myelography. ${ }^{1}$ Bolender et al found that if the crosssectional area (CSA) of the Dural sac is $100 \mathrm{~mm}^{2}$ or less on computed tomography (CT) myelography, central lumbar stenosis is present. ${ }^{2}$ The end result anatomically is reduced spinal canal dimensions and compression of the neural elements. The resultant venous congestion and hypertension likely are responsible for the symptom complex known as intermittent neurogenic claudication. ${ }^{3}$ Although having a narrow lumbar spinal canal is a necessary component of the condition, alone it is not sufficient for the disorder to be expressed, because this requires a degree of narrowing that compresses canal contents and causes compromise in sensory and motor nerve function. Mild trauma and occupational activity do not seem to affect significantly the development of this disease, but they may exacerbate a preexisting condition. Accordingly, there may be a poor correlation between "stenosis" demonstrated by neuroimaging methods and clinical symptoms.

A study by Delamarter et al found that motor and sensory deficits may develop with $50 \%$ or greater reduction of the cross sectional area of the spinal canal. ${ }^{4}$ The radiologic changes were in general more extensive than expected from clinical findings. ${ }^{5}$ Multilevel afflictions dominated both in lateral and central stenosis. The number of clinically afflicted nerve roots could not be predicted from the radiological findings.

With this background we aim to study the functional and radiological correlation in case of lumbar canal stenosis. 


\section{METHODS}

The study was approved by the Institutional review board. A prospective study of 50 cases of suspected lumbar canal stenosis presenting to Nair Hospital Mumbai, between October 2016 to April 2017 were included in the study after taking their consent.

\section{Inclusion criteria}

Inclusion criteria were radicular pain and/or neurogenic claudication with or without low back pain; above 30 years of age; central stenosis.

\section{Exclusion criteria}

Exclusion criteria for lumbar canal stenosis (LCS) studies were developmental canal stenosis; lateral recess stenosis; forminal stenosis; instability (spondylolysis or spondylolisthesis); previous fracture; vascular claudication; H/o of Diabetes, smoking and alcohol consumption; low levels of Vit B12.

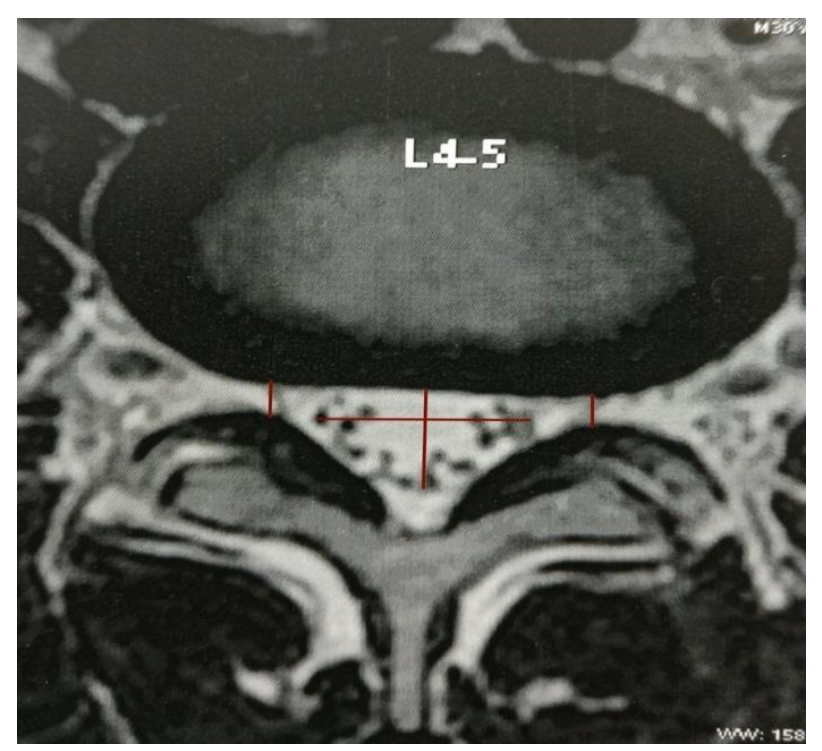

Figure 1: Foramen height, AP and transverse diameter of the dural in a axial cut at the level of disc.

All 50 patients diagnosed to have lumbar canal stenosis were evaluated for:

1. Symptoms and its duration.

2. Detailed physical examination.

i. Straight leg raising test.

ii. Detailed neurological examination.

iii. Oswestry disability index.

3. MRI of lumbosacral spine with whole spine screening. The MRI was evaluated for the following

i. AP and transverse diameter of the dural SAC in axial section at the

1. Level of the disc (Figure 1).

2. At the level of the pedicle (Figure 2).

3. Midway between level 1 and 2 (Figure 3). ii. Dural SAC cross sectional area in axial section at

1. Level of the disc.

2. At the level of the pedicle.

3. Midway between level 1 and 2 .

iii. Foraminal height in axial section.

1. At level of disc (Figure 1).

2. Midway between pedicle and disc (Figure 2).

Based on the measurement the patients were divided into

- Absolute lumbar canal stenosis as antero-posterior (AP) diameter $<10 \mathrm{~mm}$ and or dural SAC cross sectional area $<75 \mathrm{~mm}^{6}$

- Relative lumbar canal stenosis: AP diameter between $10 \mathrm{~mm}$ to $13 \mathrm{~mm}$ and or Dural sac cross sectional area between $76 \mathrm{~mm}^{2}$ to $100 \mathrm{~mm}^{2}$.

- No lumbar canal stenosis: AP diameter $>13 \mathrm{~mm}$ and or dural sac cross sectional area $>100 \mathrm{~mm}^{2}$.

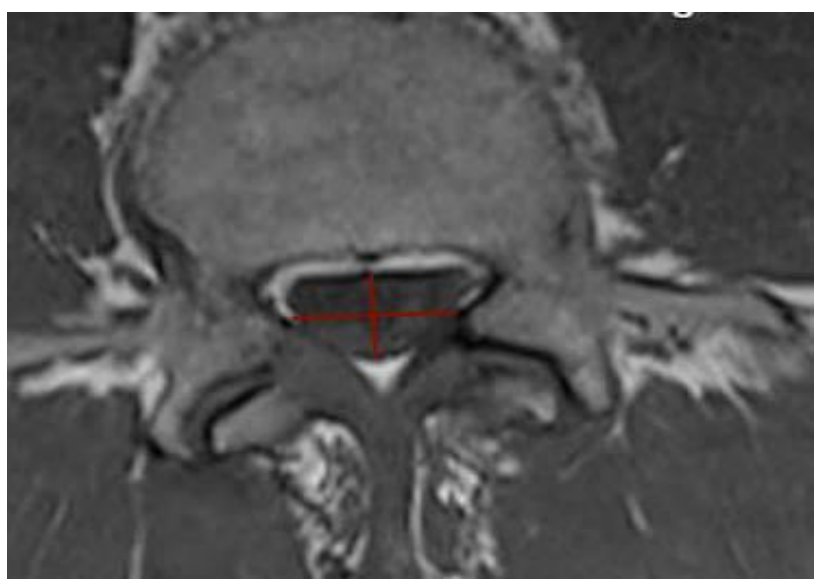

Figure 2: AP and transverse diameter of the dural in a axial cut at the level of the pedicle.



Figure 3: Foramen height, AP and transverse diameter of the dural in a axial cut at the level midway between the disc and the pedicle. 


\section{Statistical analysis}

A Chi square test was used to evaluate the relationship between ODI score and MRI findings using SPSS V 22.

\section{RESULTS}

Majority of cases were between 40-60 years of age forming $80.00 \%$ of cases (Table 1). There were $62 \%$ male vs. $38 \%$ females. Sensory deficit was complained by $64 \%$ of patients (Table 2). Straight leg raising was positive only in 2 cases (Table 3). $44 \%$ of patients had severe symptoms graded by Oswestery disability index (ODI) (Table 4). According to MRI findings, three groups were made with absolute, relative and no lumbar canal stenosis. According to ODI, patients were grouped among five functionally disabled groups with mild, moderate, severe, crippled and bed ridden patients. We observed absolute lumbar canal stenosis in $28 \%$ patients, relative lumbar canal stenosis in $36 \%$ patients and no lumbar canal stenosis in $36 \%$ patients. $50 \%$ of patients with severe ODI score had no LCS on MRI (Table 5).

Table 1: Age distribution among study participants.

\begin{tabular}{|ll|l|}
\hline Age (in years) & No. of cases & Percentage \\
\hline $\mathbf{3 0}$ & 1 & 2.00 \\
\hline $\mathbf{3 1}-\mathbf{4 0}$ & 5 & 10.00 \\
\hline $\mathbf{4 1}-\mathbf{5 0}$ & 18 & 36.00 \\
\hline $\mathbf{5 1}-\mathbf{6 0}$ & 22 & 44.00 \\
\hline$>\mathbf{6 0}$ & 4 & 8.00 \\
\hline
\end{tabular}

Table 2: Presenting symptoms.

\begin{tabular}{|lll|}
\hline Presenting symptoms & No. of cases & Percentage \\
\hline Low back pain & 35 & 70 \\
\hline Claudication & 50 & 100 \\
\hline Weakness & 20 & 40 \\
\hline Deformity & 0 & 0 \\
\hline Tingling numbness & 32 & 64 \\
\hline $\begin{array}{l}\text { Bowel bladder } \\
\text { involvement }\end{array}$ & 0 & 0 \\
\hline
\end{tabular}

Table 3: Examination findings.

\begin{tabular}{|lll|}
\hline Examination & No. of patients & Percentage \\
\hline Positive SLR test & 2 & 4 \\
\hline Sensory deficit & 18 & 32 \\
\hline Motor deficit & 10 & 20 \\
\hline Ankle jerk absent & 8 & 16 \\
\hline Extention catch & 42 & 84 \\
\hline
\end{tabular}

Table 4: ODI score.

\begin{tabular}{|llll|}
\hline ODI score & $\begin{array}{l}\text { Functional } \\
\text { disability }\end{array}$ & $\begin{array}{l}\text { No. of } \\
\text { patients }\end{array}$ & Percentage \\
\hline $\mathbf{0 \%}$ to $\mathbf{2 0 \%}$ & Minimal & 9 & 18 \\
\hline $\mathbf{2 1 \%}$ to $\mathbf{4 0 \%}$ & Moderate & 11 & 22 \\
\hline $\mathbf{4 1 \%}$ to $\mathbf{6 0 \%}$ & Severe & 22 & 44 \\
\hline $\mathbf{6 1 \%}$ to $\mathbf{8 0 \%}$ & crippled & 8 & 16 \\
\hline $\mathbf{8 1 \%}$ to $\mathbf{1 0 0 \%}$ & bedridden & 0 & 0 \\
\hline
\end{tabular}

Table 5: Co-relation between ODI scores and MRI findings.

\begin{tabular}{|c|c|c|c|c|c|}
\hline \multirow{2}{*}{ MRI findings } & \multicolumn{2}{|r|}{ ODI } & \multirow[b]{2}{*}{ Severe $40-60$} & \multirow[b]{2}{*}{ Crippled 60-80 } & \multirow[b]{2}{*}{ Bedridden $>80$} \\
\hline & Mild 0-20 & Moderate $20-40$ & & & \\
\hline $\begin{array}{l}\text { Absolute LCS }(\text { DIA }<10 \mathrm{~mm} / \\
\left.\text { Dural SAC area }<75 \mathrm{~mm}^{2}\right)\end{array}$ & 4 & 4 & 4 & 2 & 0 \\
\hline $\begin{array}{l}\text { Relative LCS (DIA } 11-13 \mathrm{~mm} / \\
\text { dural SAC area between } 76 \text { to } \\
100 \mathrm{~mm}^{2} \text { ) }\end{array}$ & 3 & 4 & 7 & 4 & 0 \\
\hline $\begin{array}{l}\text { No LCS }(\text { DIA }>13 \mathrm{~mm} / \text { dural } \\
\left.\text { SAC area }>100 \mathrm{~mm}^{2}\right)\end{array}$ & 2 & 3 & 11 & 2 & 0 \\
\hline
\end{tabular}

For statistical purpose, chi square test was applied. The null hypothesis proposed was, there is no association between functional severity and radiological findings in lumbar canal stenosis. After application of chi square test the $\mathrm{p}$ value obtained was 0.03 .

\section{DISCUSSION}

In our study we found the highest incidence in age group 51 to 60 years $(44 \%)$ followed by 41 to 50 years $(36 \%)$, $10 \%$ patients were in 31 to 40 years of age and $8 \%$ patients were above 60 years of age.
In study by Amundsen et al median age was 59 years range 16 to 77 years with 54 males 46 females. ${ }^{5}$

In study by Sirvanci et al median age was 69 years ranging from 49 to $85 .^{8}$ There was a female predominance with a male to female ratio of $1: 2$ in their study. The reason for the discrepancy may be related to the higher risk of degenerative spondylolisthesis present in females. ${ }^{11,12}$

Out of the 63 patients, 10 patients demonstrated mild disability; 13 patients moderate disability, 25 patients severe disability; 12 patients were crippled and 3 patients 
were bedridden. No correlation was found between ODI score and dural sac cross sectional area. In addition, a second comparison was performed between the subdivisions of the degree of central canal stenosis (three groups: normal, moderately stenotic and severely stenotic) and the ODI outcome which was also presented in 20 percentiles. This comparison also showed no corelation. Moreover, upon statistical evaluation of qualitative lateral radiological stenosis versus ODI.

In Athiviraham et al study there were 64 men (age range 29 to 83 years; average 65.3 years) and 59 women (range age 40 to 82 years; average 68.2 years). ${ }^{10}$

In our study $70 \%$ patients presented with low back pain while $100 \%$ patient complained of claudication. Almost $86 \%$ patients had complaints of sciatica. Around $80 \%$ patients reported improvement in symptoms on bending forward while $64 \%$ patients complained the tingling numbness. $40 \%$ patients complained weakness in lower extremity. On clinical examination extension catch was observed in $84 \%$ of patients and sensory deficit was found in $76 \%$ of patients. Motor deficit was found in $20 \%$ patients. Ankle jerk was absent in $16 \%$ of patients. The straight leg rising test was not positive in any of the patients.

In study by Amundsen et al $95 \%$ patients presented with lumbar pain, $70 \%$ patients had sensory disturbance in legs, $33 \%$ patients had voiding disturbance, $91 \%$ patients had claudication, $61 \%$ patients had relief of pain by bending forwards and $40 \%$ patients complained worsening of pain on walking downhill. ${ }^{5}$ Deformity like scoliosis was found in $56 \%$ patients, sensory dysfunction in $51 \%$ patients, reduced reflexes in $47 \%$ of patients, lumbar tenderness in $40 \%$ of patients, reduced spinal mobility in $36 \%$ of patients, straight leg raising test was positive in $24 \%$ of patients, paresis in legs in $23 \%$ of patients while perianal numbness in $6 \%$ of patients.

In Weishaupt et al study, 10 of the 30 patients (33\%) had only low back pain, 19 patients $(63 \%)$ had predominantly radicular pain, five patients $(17 \%)$ had reflex deficits, 14 patients had sensory deficits $(47 \%)$, two patients had motor deficits $(7 \%)$, and one patient had pseudoradicular pain $(3 \%)^{7}$

In our study ODI was calculated and seen that minimal functional disability $(0-20 \%)$ was seen in $18 \%$ of patients, moderate $(21-40 \%)$ in $22 \%$ of patients, $44 \%$ patients were having severe functional disability (41$60 \%$ ) and $16 \%$ patients were crippled (61-80\%). $36 \%$ patients had VAS score less than $50 \%$ and $64 \%$ patients had VAS score more than $50 \%$.

Lohman et al found the number of levels with absolute or relative spinal stenosis did not correlate to the clinical symptoms. ${ }^{9}$ There was no correlation between ODI scores and degree of narrowing in patients with and without spondylolisthesis. The number of levels that were defined as stenotic also had no correlation with the ODI scores. This reinforces the fact that one should treat the Patient and not the MRI.

\section{CONCLUSION}

Lumbar canal stenosis is predominant in males. It is predominantly present in age group 51-60 years. Most common presenting symptoms are claudicant pain in lower limbs, low backache and tingling numbness. Most common clinical examination finding is extension catch and sensory deficit (dermatomal/ non-dermatomal). There is no statistical co-relationship found between clinical and radiological features of lumbar canal stenosis.

\section{Funding: No funding sources \\ Conflict of interest: None declared}

Ethical approval: The study was approved by the institutional ethics committee

\section{REFERENCES}

1. Verbiest H. Results of surgical treatment of idiopathic developmental stenosis of the lumbar vertebral canal. A review of twenty-seven years' experience. J Bone Joint Surg Br. 1977;59:181-8.

2. Bolender NF, Schonstrom NS, Spengler DM. Role of computed tomography and myelography in the diagnosis of central spinal stenosis. J Bone Joint Surg Am. 1985;67(2):240-6.

3. Wilson CB, Ehni G, Grollmus J. Neurogenic intermittent claudication. Clin Neurosurg. 1971;18:62-85.

4. Delamarter RB, Bohlman HH, Dodge LD, Biro C. Experimental lumbar spinal stenosis. Analysis of the cortical evoked potentials, microvasculature, and histopathology. J Bone Joint Surg Am. 1990;72:110-20.

5. Amundsen $\mathrm{T}$, Weber $\mathrm{H}$, Lilleås $\mathrm{F}$, Nordal $\mathrm{HJ}$, Abdelnoor M, Magnaes B. Lumbar spinal stenosis: clinical and radiologic features. Spine. 1995;20:1178-86.

6. Arbit E, Pannullo S. Lumbar stenosis. A clinical review. Clin Orthop Relat Res. 2001;384:137-43.

7. Weishaupt D, Schmid MR, Zanetti M. Positional MR Imaging of the lumbar spine: does it demonstrate nerve root compromise not visible at conventional MR Imaging? Radiology. 2000;215:247-53.

8. Sirvanci M, Bhatia M, Ganiyusufoglu KA. Degenerative lumbar spinal stenosis: correlation with Oswestry Disability Index and MR imaging. Eur Spine J. 2008;17:679-85.

9. Lohman CM, Tallroth K, Kettunen JA, Lindgren K. Comparison of Radiologic Signs and Clinical Symptoms of Spinal Stenosis. Spine. 1995;31(16):1834-40.

10. Athiviraham A, Scott C, Soboleski D, Yen D. Clinical correlation of radiologic spinal stenosis 
after standardization for vertebral body size. Clin Radiol. 2007;62(8):776-80.

11. Karantanas AH, Zibis AH, Papaliaga M, Georgiou E, Rousogiannis S. Dimensions of the lumbar spinal canal: variations and correlations with somatometric parameters using CT. Eur Radiol. 1998;8(9):1581-5.

12. Kornblum MB, Fischgrund JS, Herkowitz HN. Degenerative lumbar spondylolisthesis with spinal stenosis: a prospective long-term study comparing fusion and pseudarthrosis. Spine. 2004;29:726-33.

Cite this article as: Hussain N, Patil ND, Shakya A, Saindane KP. Does functional evaluation and magnetic resonance imaging finding in a case of lumbar canal stenosis co-relate: a study of 50 cases. Int J Res Orthop 2017;3:751-5. 